\title{
Solid-Phase Polycondensation of Aromatic Bisphenylurethane and Aromatic Diamine
}

\author{
Keikichi Uno, Kazuma Niume, Tetsuo Nakayama, \\ and Yoshio Iwakura \\ Department of Synthetic Chemistry, Faculty of Engineering, \\ Tokyo University, Bunkyo-ku, Tokyo, Japan.
}

(Received October 6, 1973)

\begin{abstract}
Thermostable polyureas which possess a benzimidazole ring in the main chain have been prepared by the solid-phase polycondensation of the coprecipitate of bisphenylurethane, 2, 2'-di-p- $N$-phenoxycarbonylaminophenyl-5, $5^{\prime}$-bibenzimidazole, and diamines. The solid-phase reaction, the decomposition of phenylurethane followed by the reaction with diamine, was investigated by DTA, TGA and DSC. The polymerization proceeded in two stages and the activation energy of the latter stage was much larger than the former. The rate-determining factor was concluded to be the diffusition of each reactant in the latter part of the reaction. The dissociation of phenylurethane was activated by amine also in the solid-phase reaction and the activation energy was in good agreement with those obtained in amine solutions.

KEY WORDS Benzimidazole / Polyurea / Isocyanate Generator / DSC / Thermal Stability / Polycondensation / Solid-Phase Polycondensation /
\end{abstract}

$O$-Phenylurethanes are known to give isocyanates at high temperature and have been used as isocyanate generators or precursors of isocyanates. Polycondensation reactions of $N$ phenoxycarbonylamino $\operatorname{acid}^{1}$ (eq 1$)$ and $N$ - thiophenoxycarbonylamino $\operatorname{acid}^{2}$ (eq 2) to prepare polypeptides are known as examples of the polymer synthesis applying the reaction of phenylurethanes.

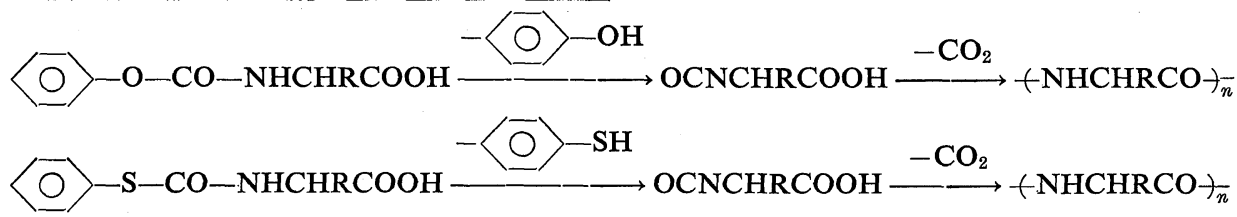

However, little has been reported about the synthesis of polyurea using the bisphenylurethane as one component.

The synthesis of a diisocyanate having a benzimidazole ring was first attempted in the preparation of polymers having a benzimidazole ring in the main chain, but the attempt was unsuccessful because the diisocyanate could not be isolated from polar solvents. Accordingly, a bisphenylurethane with benzimidazole rings, precursor of isocyanate, was synthesized in order to prepare polyureas by polycondensation reactions with diamines.

Diamine $(\mathbf{I})$ with benzimidazole rings was prepared from 3, $3^{\prime}$-diaminobenzidine and $p$-aminobenzoic acid in polyphosphoric acid (PPA).,4 Bisphenylurethane(II or BPU) was prepared by the reaction of the diamine with phenylchloroformate.<smiles>Cc1ccc2[nH]c(-c3ccc(N)cc3)nc2c1</smiles> 
The attempt to produce a polycondensation reaction of bisphenylurethane(II) with diamine(I) in solution was unsuccessful because of the precipitation of low-molecular-weight oligomer. On the other hand, it was found that isocyanate(III) was formed by the decomposition of the bisphenylurethane at high temperature. Equimolar amounts of $I$ and II were therefore mixed well in a mortar of agate and heated under vacuum to give polyurea(IV). The polycondensation reaction appeared to proceed in the solid phase.
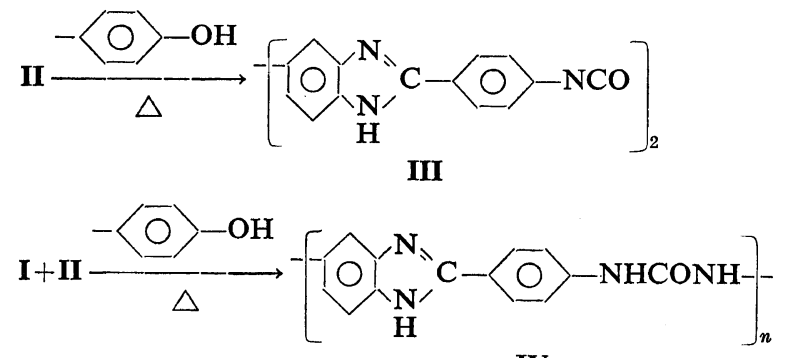

In the present paper, the chemical behavior of bisphenylurethane at high temperature and its polycondensation with diamines are described. The mechanism of the apparent solid-phase polycondensation reaction was also discussed in detail.

\section{IV}

\section{RESULTS AND DISCUSSION}

\section{Preparation of Phenylurethane}

Monofunctional phenylurethane for the model reaction was prepared according to the following eq 6 and 7.

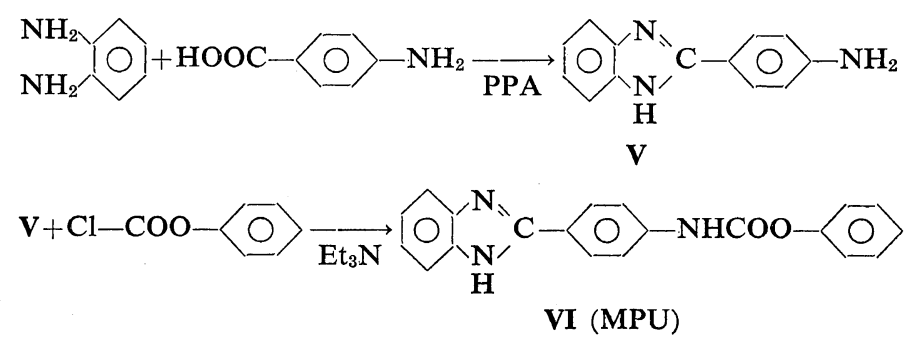

The bisphenylurethane used in the polycondensations was prepared according to eq 3 . The results of these reactions are listed in Table $I$. In the preparation of monophenylurethane(VI or MPU), both the amine(V) and its product MPU were soluble in the usual organic solvents and the best result was obtained when tetrahydrofuran (THF) was used as a solvent. On the other hand the bifunctional diamine(I) and its bisphenylurethane (BPU) were scarecely soluble in the usual organic solvents but were soluble in highly polar solvents such as dimethylformamide (DMF), dimethylacetamide (DMAc) and hexamethylphosphoramide (HMPA). However, DMF and DMAc were found to react with phenylchloroformate to some extent at room temperature and the bisphenylurethanes formed could not
Table I. Preparation of phenylurethane

\begin{tabular}{|c|c|c|c|c|c|}
\hline \multirow{2}{*}{$\begin{array}{l}\text { Phenylure } \\
\text { thane }\end{array}$} & \multicolumn{3}{|c|}{ Reaction conditions } & \multirow{2}{*}{$\underset{\%}{\text { Yield, }}$} & \multirow{2}{*}{$\underset{{ }^{\circ} \mathrm{C}}{\mathrm{mp}}$} \\
\hline & Solvent & $\underset{{ }^{\circ} \mathrm{C}}{\text { Temp }}$ & $\underset{\mathrm{hr}}{\text { Time, }}$ & & \\
\hline \multirow{3}{*}{ MPU } & Dioxane $R$ & Room temp & 5 & 53.1 & 240 \\
\hline & HMPA & $0-3$ & 8 & 67.3 & 239 \\
\hline & THF & $0-2$ & 5 & 88.5 & 240 \\
\hline \multirow{4}{*}{ BPU } & DMF & $0-4$ & 5 & - & - \\
\hline & DMAc & $0-2$ & 5 & - & - \\
\hline & HMPA & $0-3$ & 5 & 15.8 & $>400$ \\
\hline & HMPA-TI & THF $0-2$ & 5 & 65.3 & $>400$ \\
\hline
\end{tabular}

be obtained in the pure state. The reaction was therefore carried out in HMPA. A better result was obtained when THF (half the volume of 
HMPA) was added to prevent the solidification of HMPA (mp $7.2^{\circ} \mathrm{C}$ ) at the low reaction temperature $\left(0-5^{\circ} \mathrm{C}\right)$. The formation of phenylurethanes was confirmed by the elementary analyses and the characteristic absorption band of urethane around $1720 \mathrm{~cm}^{-1}$ in the infrared spectra.

\section{Thermal Dissociation of Phenylurethanes}

It is well known that phenylurethanes are decomposed thermally to give isocyanate at high temperatures. When BPU was heated at $280^{\circ} \mathrm{C}$ under reduced pressure, the characteristic absorption band of urethane around $1720 \mathrm{~cm}^{-1}$ entirely disappeared and a new absorption band characteristic of isocyanate appeared at 2260 $\mathrm{cm}^{-1}$. These observations show that the diisocyanate(III) was prepared by the thermal decomposition of bisphenylurethane(II) at high temperature.

DTA-TGA curves of urethanes, MPU and BPU, are shown in Figure 1. Two endothermic peaks were observed in the DTA curve of MPU. The temperature of the second peak on MPU

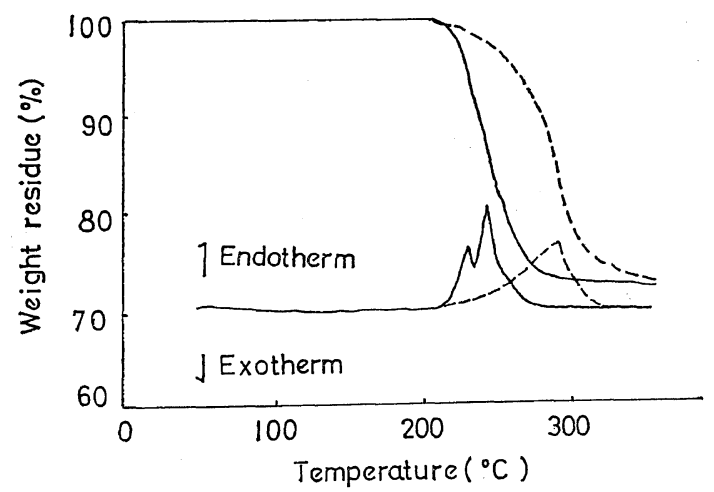

Figure 1. DTA and TGA curves for the decomposition MPU and BPU: - - MPU; -----, BPU. coincided with the temperature at which the rate of weight loss was a maximum in the TGA curve. Consequently, the lower-side endothermic peak was attributed to the melting phenomenon of MPU and the higher-side one to its decomposition. Thermogravimetric analysis showed that MPU began to decompose at about $200^{\circ} \mathrm{C}$ and the decomposition ended at around $280^{\circ} \mathrm{C}$. The weight loss observed for this temperature range corresponded to the weight of eliminated phenol when it is assumed that MPU dissociated into isocyanate and phenol. From these results, MPU was confirmed to melt at $231^{\circ} \mathrm{C}$ and rapidly dissociate into isocyanate.

In the DTA curve of BPU in Figure 1 only one endothermic peak was observed at about $290^{\circ} \mathrm{C}$. The weight loss observed in the TGA curve began at about $200^{\circ} \mathrm{C}$ and continued until $310^{\circ} \mathrm{C}$, and corresponded to the amount of the phenol eliminated from BPU, showing that BPU was decomposed into isocyanate(III) and phenol when it was heated. These data agreed with the above-mentioned infrared spectroscopy. The decomposition of BPU appeared to proceed in the solid state throughout the reaction and the endotherm in the DTA curve was attributed to the decomposition.

The Reaction of Phenylurethane and Amine

Finely powdered phenylurethane, MPU and amine $(\mathbf{V})$ were mixed well in a agate mortar and heated at about $200^{\circ} \mathrm{C}$ under reduced pressure to give urea derivatives. The elimination of phenol was observed but the reaction system remained in solid phase without any apparent melting phenomenon. Table II lists the reaction conditions and the results of elementary analyses of the products.

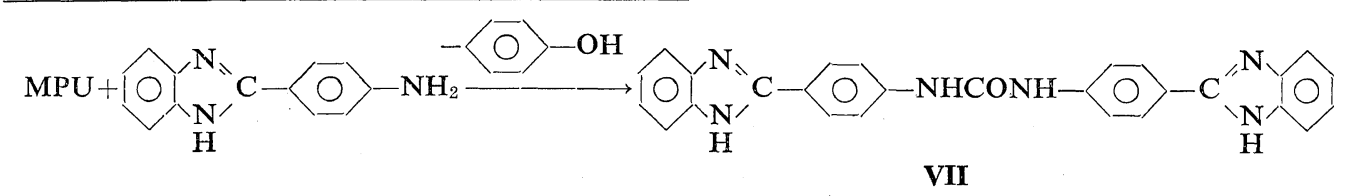

Table II. Preparation of urea

\begin{tabular}{|c|c|c|c|c|c|}
\hline \multirow{2}{*}{$\begin{array}{l}\text { Reaction condition, } \\
{ }^{\circ} \mathrm{C} / \mathrm{mmHg} / \mathrm{hr}\end{array}$} & \multirow{2}{*}{$\begin{array}{l}\text { Yield, } \\
\%\end{array}$} & \multirow{2}{*}{$\begin{array}{l}\text { Dec temp., } \\
{ }^{\circ} \mathrm{C}\end{array}$} & \multicolumn{3}{|c|}{ Elementary analysis } \\
\hline & & & $\mathrm{C}, \%$ & $\mathrm{H}, \%$ & $\mathrm{~N}, \%$ \\
\hline $220 / 1 / 1$ & 92.6 & $335-336$ & $\begin{array}{lr}\text { Calcd } & 72.59 \\
\text { Found } & 72.32\end{array}$ & $\begin{array}{l}4.54 \\
4.71\end{array}$ & $\begin{array}{l}18.91 \\
18.61\end{array}$ \\
\hline
\end{tabular}


Solid-Phase Polycondensation of Aromatic Bisphenylurethane and Aromatic Diamine

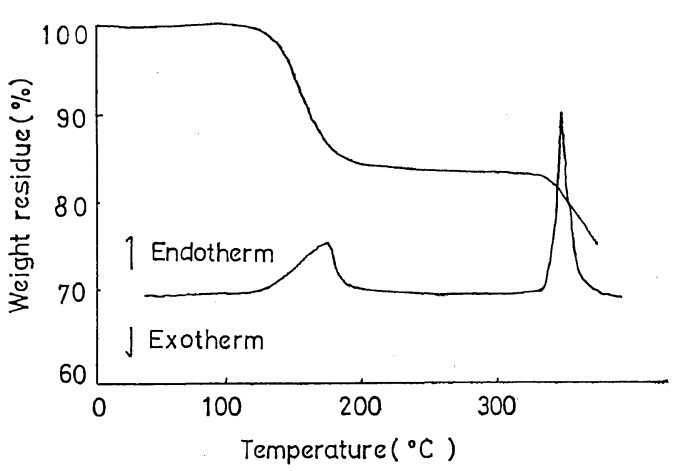

Figure 2. DTA and TGA curves for the reaction of MPU and amine(V).

Figure 2 shows the DTA-TGA curves of the reaction in the above system. DTA curve had two endothermic peaks. The former peak at $180^{\circ} \mathrm{C}$ was attributed to the decomposition of MPU and another peak around $325^{\circ} \mathrm{C}$ seemed to be due to the melting or the decomposition of the urea formed. The decomposition temperature of MPU in this case was depressed by about $50^{\circ} \mathrm{C}$ when it was compared with the case of MPU without amine. A weight loss equal in amount to the eliminated phenol was observed in the TGA curve at the temperature which corresponded to the lower-side endothermic peak in the DTA curve. These results and the infrared spectrum showed that the urea derivative(VII) was prepared by the reaction MPU and amine $(\mathbf{V})$.

From the reaction of urethane with amine in solution presented by Mukaiyama, ${ }^{5}$ the proceeding of the present solid-state reaction was considered as follows; MPU was decomposed below its melting temperature under the catalytic influence of amine, and the isocyanate formed reacted with the amine, yielding the urea derivatives with higher melting point.

The comparison of Figure 1 with Figure 2 shows that the decomposition of MPU was promoted by the amine just as in the amine solution. ${ }^{5}$ The similar promotion of the decomposition of BPU by diamine(I) was observed in the polycondensation reaction (eq 5), as shown in Figure 5.

\section{Polycondensation}

BPU and diamine(I) were mixed well in a agate mortar and heated under reduced pressure to prepare polyurea. The results are listed in Table III, showing that polyureas were derived from BPU and diamines. The formation of the polyureas was confirmed by the analytical data, infrared spectra, viscosities and the weight loss of the reaction system in TGA. It is noteworthy that polyureas could be derived by heating the mechanically mixed powder of BPU and diamine(I), because even in the solid phase each component diffused enough to react to form high-molecular-weight polymer. The inherent viscosity increased with prolonged reac-

Table III. Preparation of polyurea

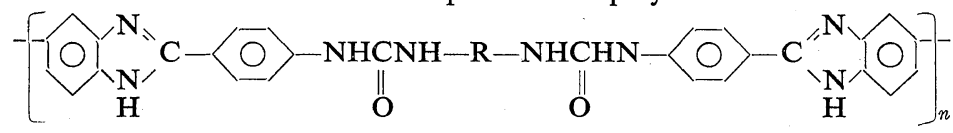

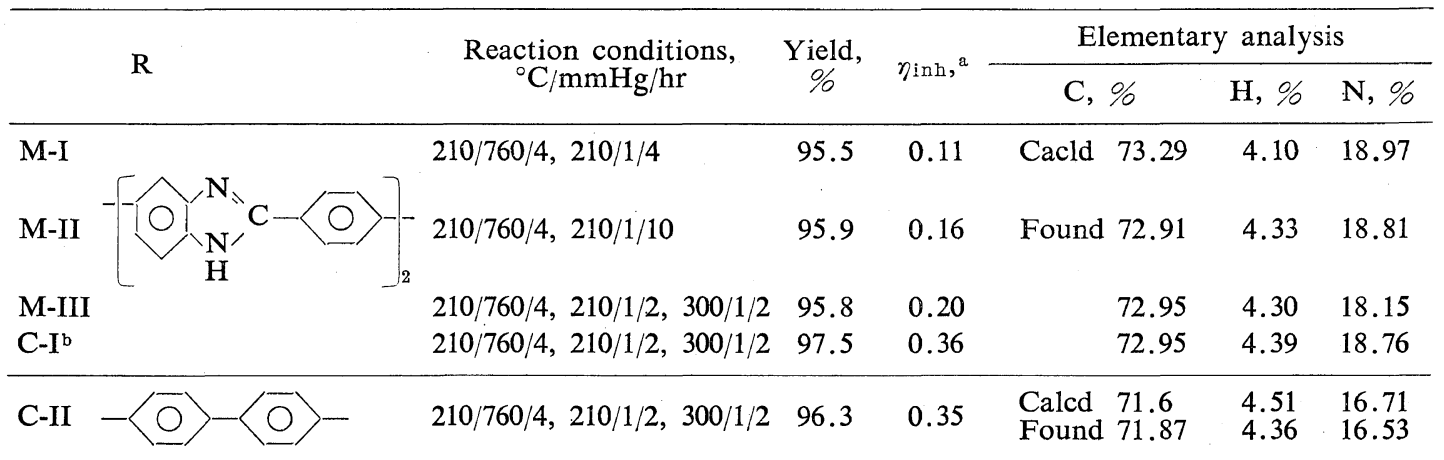

a In sulfuric acid.

b Coprecipitate of BPU and diamine(I). 


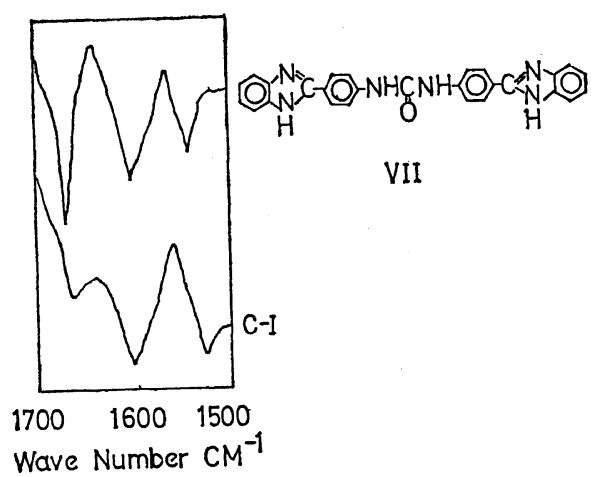

Figure 3. Infrared spectra of ureas.

tion time, showing that this solid-phase polymer formation reaction is a successive polycondensation.

In the experiments of C-series in Table III, polymerization was carried out using the coprecipitate of both components, prepared by adding a methanol-water mixture $(1: 1)$ to the equimolar HMPA solution of BPU and diamine(I) and by subsequent drying. Both yields and viscosities were larger than those from mechanically mixed system. In order to know the structure of the coprecipitate, it was investigated by X-ray analysis. The diagram was shown in

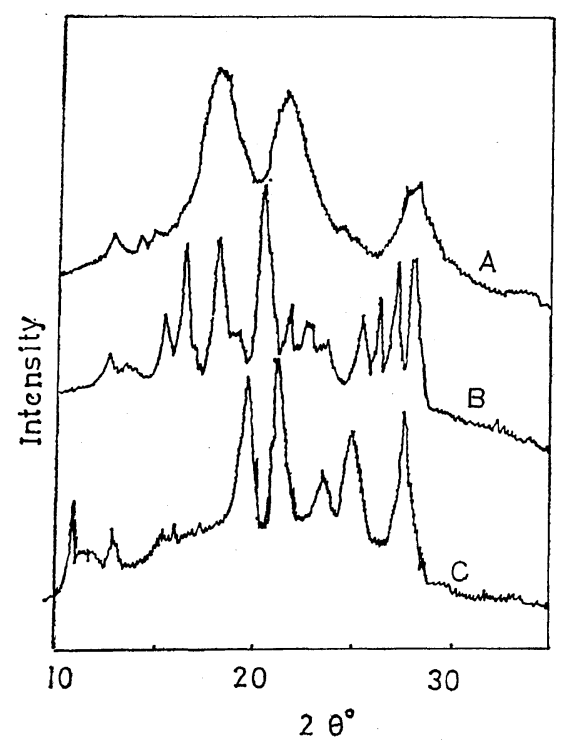

Figure 4. X-ray diffraction diagram: A, BPU; B, diamine(I); C, coprecipitate.
Figure 4 with that of BPU and diamine(I). The X-ray diffraction diagram of the coprecipitate was different from the addition of the component diagrams. Some diffractions had not originated from either component. Consequently both components are considered to have been mixed at almost the molecular level. The coprecipitate was changed into an almost amorphous form when it was well ground in the agate mortar. In the subsequent polycondensation, the mixture obtained by coprecipitation followed by grinding was used for the reaction.

The DTA-TGA curves for the reaction of the coprecipitate are shown in Figure 5. The

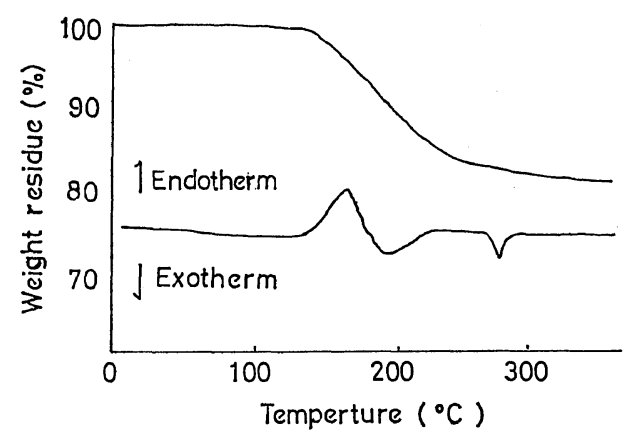

Figure 5. DTA and TGA curves for the reaction of BPU with diamine(I).

TGA curve showed that the weight continued to decrease in the wide temperature range from $160^{\circ} \mathrm{C}$ to over $300^{\circ} \mathrm{C}$. In the DTA curve, one large endothermic peak at around $170^{\circ} \mathrm{C}$ and two exothermic peaks at around $190^{\circ} \mathrm{C}$ and $280^{\circ} \mathrm{C}$ were observed. However, when equimolar amount of BPU and diamine(I) were put together in a DTA cell without mixing the exothermic peaks were not ovserved and the endothermic peak was observed at around $290^{\circ} \mathrm{C}$; the same temperature range as in the decomposition of BPU without amine in Figure 1. Consequently, the exotherms (in Figure 5) were attributed to the reaction of the formed diisocyanate and diamine(I).

In order to clarify the observations and to investigate the solid-phase reaction in more detail, the reaction was followed by DSC as shown in Figure 6. The amounts of endotherm and exotherm of the reaction were estimated 
Solid-Phase Polycondensation of Aromatic Bisphenylurethane and Aromatic Diamine

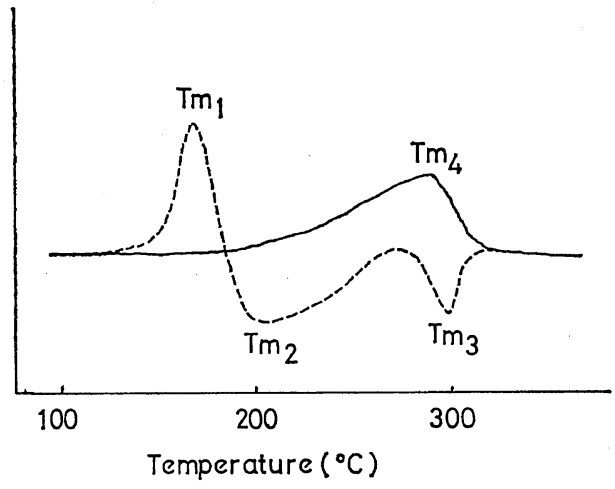

Figure 6. DSC curves; - - BPU; --.--, the reaction of BPU with diamine(I).

from the DSC thermograms. The ratio of the second-stage exotherm reaction to the total exothermic reaction was calculated to be about $30 \%$. The result indicated that about $30 \%$ of the reactive isocyanate was shown to remain unreacted at the high temperature range in spite of the presence of an equal amount of the amino group in the reaction system, and to react with the amino groups above $280^{\circ} \mathrm{C}$. In order to investigate this unusual phenomenon, samples from before and after the second exothermic peak were taken from the DSC system. In the infrared spectrum of the sample which was taken at $280^{\circ} \mathrm{C}$, the characteristic absorption band of isocyanate around $2260 \mathrm{~cm}^{-1}$ was observed clearly but the absorption band of urethane around $1720 \mathrm{~cm}^{-1}$ had disappeared entirely. However, the isocyanate group was not detected in the infrared spectrum of the sample which was taken at $350^{\circ} \mathrm{C}$. The inherent viscosity of the sample increased from 0.05 to 0.27 after the second endothermic peak.

The activation energies of the reactions were estimated from DSC thermograms by Kissinger's $\operatorname{method}^{6}$ (Figure 7). The values obtained are listed in Table IV. The activation energy was also estimated by Frazer's method, measuring the rate of weight loss of BPU by TGA at constant temperatures and the values are listed in the parentheses in Table IV. The values obtained from both method were in fair agreement with each other.

On the reaction of urethane with amine in solution, the activation energy was estimated to

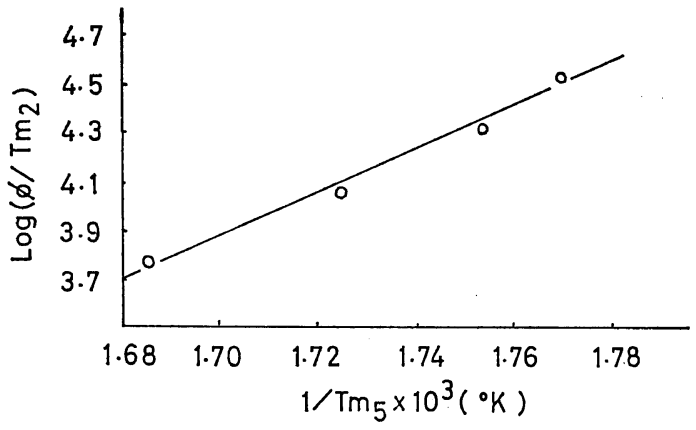

Figure 7. $\log \left(\phi / \operatorname{Tm}^{2}\right)-1 / T$ plot.

Table IV. Activation energy

\begin{tabular}{lc}
\hline$T m$ & $E, \mathrm{kcal} / \mathrm{mol}$ \\
\hline$T m_{1}$ & $18(23)$ \\
$T m_{2}$ & 21 \\
$T m_{3}$ & 59 \\
$T m_{4}$ & $45(39)$ \\
\hline
\end{tabular}

be $21 \mathrm{kcal} / \mathrm{mol}$ and the rate-determining step was shown to be the amine-catalyzed dissociation of urethane. ${ }^{5}$ The value of the activation energy $(18 \mathrm{kcal} / \mathrm{mol})$ of the decomposition reaction of BPU in the present study was close to this value.

The addition of isocyanate with amine $\left(\mathrm{Tm}_{2}\right)$ which followed the decomposition of the urethane gave the activation energy to be $21 \mathrm{kcal} / \mathrm{mol}$. As the reaction of isocyanate with amine is a very fast exothermic reaction, it is unreasonable to assume that the activation energy of the addition reaction was larger than that of the dissociation of the urethane. Moreover, the activation energy of the reaction of the remaing $30 \%$ of the isocyanate with diamine(I) was as large as $59 \mathrm{kcal} / \mathrm{mol}$. It was concluded that the rate-determining factor for the reaction of the diisocyanate with diamines in the solid phase was the diffusion of each reactant.

In the present solid-phase reaction, the reaction of the closely situated isocyanate and amino groups must have proceeded first. According to the above assumption, about $70 \%$ of the isocyanate and amino groups in the system were reacted in the first stage and oligomers were prepared. The oligomerization of BPU and diamine(I) possibly retarded the movement of 
the main chain and suppressed the reaction of the isocyanate and amino groups of the oligomers at the end of the first-stage reaction. The remaining $30 \%$ of the addition reaction proceeded in the second stage at a higher temperature. As a consequence the $T g$ of the present polyurea having a benzimidazole ring in the main chain is considered to be the range $280-300^{\circ} \mathrm{C}$.

\section{The Properties of the Polyureas}

Table $\mathrm{V}$ listed the properties of the polyureas obtained. They were soluble in concentrated sulfuric acid and partly soluble in DMAc. They were also heat-resitant polyureas.

Table V. Property of polyurea

\begin{tabular}{lccccc}
\hline & $\mathrm{H}_{2} \mathrm{SO}_{4}$ & \multicolumn{3}{c}{ Solubility } & Dec temp, \\
\cline { 3 - 5 } & & DMAc & HMPA & DMF & ${ }^{\circ} \mathrm{C}$ \\
\hline M-III & +- & +- & - & - & 440 \\
C-I & ++ & +- & - & - & 480 \\
C-II & ++ & +- & - & - & 460 \\
\hline
\end{tabular}

a ++ , soluble at room temperature; +- , partially soluble by heating; - insoluble.

b Temperature at which rapid weight loss was observed in TGA.

\section{EXPERIMENTAL}

\section{Monomers and Model Compound \\ 2-p-N-Phenoxycarbonylaminophenylbenzimidazole.} 2-p-Aminophenylbenzimidazole $(10.5 \mathrm{~g})$ was dissolved in $300 \mathrm{ml}$ of THF. After the solution was cooled with ice, triethylamine $(5.1 \mathrm{~g})$ was added dropwise with stirring while keeping the temperature below $5^{\circ} \mathrm{C}$. After being kept at this temperature for $5 \mathrm{hr}$ with stirring, THF was evaporated. The residue was washed repeatedly with ether and extracted with a small amount of activated charcoal. Warm water was added to the solution until a white precipitate began to form. After being stood overnight the precipitate was collected by filtration. The yield was $14.7 \mathrm{~g} \mathrm{(89 \% ),} \mathrm{mp} 240^{\circ} \mathrm{C}$.

Anal. Calcd for $\mathrm{C}_{20} \mathrm{H}_{15} \mathrm{~N}_{3} \mathrm{O}_{2}$ :

C, $72.93 \% ; \mathrm{H}, 4.59 \% ; \mathrm{N}, 12.76 \%$.

Found: $\mathrm{C}, 72.81 \% ; \mathrm{H}, 4.68 \% ; \mathrm{N}, 12.69 \%$.
2, $2^{\prime}$-di-p-N-Phenoxycarbonylaminophenyl-5, $5^{\prime}$ bibenzimidazole. $\quad 2,2^{\prime}$-p-diaminophenyl-5, $5^{\prime}$ bibenzimidazole $(2.1 \mathrm{~g})$ was dissolved in $80 \mathrm{~m} l$ of the equal volume solution of THF and HMPA. After the solution was cooled to $0^{\circ} \mathrm{C}$, triethylamine $(1.1 \mathrm{~g})$ was added. Phenylchloroformate $(1.7 \mathrm{~g})$ in $20 \mathrm{ml}$ of THF was added to the solution, and held at this temperature for $5 \mathrm{hr}$ with stirring. The resulting triethylamine hydrochloride was filtered. Methanol $(200 \mathrm{~m} l)$ was added to the solution followed by the addition of $250 \mathrm{ml}$ of warm water $\left(70^{\circ} \mathrm{C}\right)$. The resulting precipitate was collected by centrifuge and was washed with a mixture of methanol and water $(1: 1)$ and dried. It was again dissolved in $80 \mathrm{~m} l$ of DMF and the solution was treated with active charcoal. Methanol $(160 \mathrm{ml})$ was added to the solution and the addition of warm water yielded a yellow product.

Anal. Calcd for $\mathrm{C}_{40} \mathrm{H}_{28} \mathrm{~N}_{6} \mathrm{O}_{4}$ :

$\mathrm{C}, 73.16, \mathrm{H} ; 4.30, \mathrm{~N} ; 12.86$.

Found: $\mathrm{C} ; 72.75, \mathrm{H} ; 4.85, \mathrm{~N} ; 12.87$.

\section{Polycondensation}

$M-I I I$. Equal molar diamine(I) $(0.416 \mathrm{~g})$ and BPU $(0.656 \mathrm{~g})$ were mixed well in an agate mortar. The resultant mixture $(0.5 \mathrm{~g})$ was put into a flask fitted with a nitrogen inlet tube and was heated in a flask in an atmosphere of nitrogen at $210^{\circ} \mathrm{C}$ for $4 \mathrm{hr}$. It was then heated at $210^{\circ} \mathrm{C}$ for $2 \mathrm{hr}$ and $300^{\circ} \mathrm{C}$ for $2 \mathrm{hr}$ under a vacuum $(1 \mathrm{mmHg})$. The resultant polymer was washed with methanol and dried. It weighed $0.397 \mathrm{~g}$ and had an inherent viscosity of 0.20 $\left(0.2 \%\right.$ in $\mathrm{H}_{2} \mathrm{SO}_{4}$ at $\left.30^{\circ} \mathrm{C}\right)$. It did not melt below $450^{\circ} \mathrm{C}$.

$C-I . \quad 2,2^{\prime}$ - Bis - $p$ - $N$ - phenoxycarbonylaminophenyl-5, $5^{\prime}$-bibenzimidazole $\left(3.23 \mathrm{~g}\right.$ ) and $2,2^{\prime}$ $p$-diaminophenyl-5, $5^{\prime}$-bibenzimidazole $\quad(2.05 \mathrm{~g})$ were dissolved completely in $9 \mathrm{~g}$ of HMPA with stirring at $50^{\circ} \mathrm{C}$. The same quantity of methanol as the HMPA was added to the solution and then the same volume of hot water $\left(70^{\circ} \mathrm{C}\right)$ was added with vigorous stirring. The resulting precipitate was collected by centrifuge, washed with a $1: 1$ solution of water and methanol and dried to obtain the equal molar mixture of BPU and diamine(I). $\quad 0.7-\mathrm{g}$ mixture thus obtained was heated in the same way as in the experiment M-III. The polymer obtained weighed 
Solid-Phase Polycondensation of Aromatic Bisphenylurethane and Aromatic Diamine

$0.56 \mathrm{~g}$, and had an inherent viscosity of 0.36 $\left(0.2 \%\right.$ in $\mathrm{H}_{2} \mathrm{SO}_{4}$ at $\left.30^{\circ} \mathrm{C}\right)$. It did not melt below $450^{\circ} \mathrm{C}$, but decomposed gradually at $370^{\circ} \mathrm{C}$.

DTA-TGA Measurements

DTA-TGA measurements were run on a Rigakudenki-8021 Thermal Analyzer.

DSC Measurements

DSC results were obtained using a PerkinElmer Differential Scanning Calorimeter (DSC1B).

\section{REFERENCES}

1. Y. Ishizuka, Nihon Kagaku Zasshi (J. Chem. Soc. Japan, Pure Chem. Sect.), 76, 802 (1955).

2. J. Noguchi, S. Ishino, T. Hayakawa, and $\mathbf{M}$. Iida, ibid., 76, 475 (1955).

3. D. W. Hein, R. J. Alheim, and J. J. Leavitt, J. Amer. Chem. Soc., 79, 427 (1957).

4. Y. Iwakura, K. Uno, Y. Imai, and M. Fukui, Makromol. Chem., 77, 41 (1964).

5. T. Mukaiyama and Y. Hoshino, J. Amer. Chem. Soc., 78, 1946 (1956).

6. H. E. Kissinger, Anal. Chem., 29, 1702 (1957).

7. A. E. Frazer and I. M. Sarason, J. Polym. Sci. Part A-1, 4, 1649 (1966). 